\title{
Hepatite infecciosa canina: relato de caso Infectious canine hepatitis: case report
}

\author{
Tathiana Mourão Anjos Piacesi, “Júlio César Cambraia Veado*, Cecília Muller Bandeira, ${ }^{* *}$ Rubens Antônio Carneiro, ${ }^{* *}$ \\ Fernando Antônio Bretas Viana, ${ }^{* *}$ Adriane Pimenta da Costa Val Bicalho**
}

\begin{abstract}
Resumo
A hepatite infecciosa canina é uma enfermidade que provoca lesões nas células endoteliais de diversos tecidos e hepáticas, culminando com sinais clínicos como hemorragias e icterícia, além de alterações das funções renal, hepática e gastrintestinais. É de ocorrência rara, mesmo naqueles animais não vacinados ou jovens e, por isso, não é comum o clínico médico-veterinário suspeitar deste diagnóstico, não solicitando exames laboratoriais confirmatórios. O presente trabalho descreve a manifestação clínica e o tratamento aplicado a um animal portador de hepatite infecciosa canina.
\end{abstract}

Palavras-chave: hepatite infecciosa canina, adenovírus canino tipo 1, hemorragia, cães.

\begin{abstract}
Infectious canine hepatitis is an infirmity that causes injuries in endothelial and hepatic cells, culming with signs like hemorrhages and icterus, further renal, hepatic and gastrointestinal functions alterations. It rarely occurs, same in not vaccined or young animals and hence is not Veterinary Doctor routine suspecting of this diagnostic and to request confirmatory laboratorial exam. The present paper describes the clinical manifestation and the prescribed treatment to alnfectious canine hepatitis animal porter.
\end{abstract}

Keywords: infectious canine hepatitis, canine adenovirus 1, hemorrhage, dogs.

\section{Revisão de Literatura}

\section{Introdução}

A hepatite infecciosa canina ou doença de Rubarth é uma doença viral multissistêmica, causada pelo adenovírus canino tipo 1 (CAV-1). Já há muito tempo é reconhecida como causa de necrose hepática aguda em cães. Os animais acometidos são os cães e outras espécies das famílias Canidae e Ursidae (In 1962). A hepatite infecciosa foi originalmente descrita por Rubarth em 1947, na Suécia, como uma doença aguda, muitas vezes fatal, que causava lesões no fígado, tecido linfóide e endotélio vascular em caninos. Foi por ele chamada de hepatite contagiosa dos cães (Parry, 1950; Pay, 1950). Rubarth chamou atenção para o fato que o vírus da encefalite enzoótica das raposas era idêntico ao vírus da hepatite canina (Hipólito e Freitas,1964).

\section{Etiologia e Epidemiologia}

O CAV-1 é um vírus DNA de fita dupla, não envelopado, com aproximadamente 70-90nm de diâmetro, pertencente à família Adenoviridae (Quinn, 2005). A incidência da moléstia clínica causada por CAV-1 é atualmente muito baixa, devido à eficácia dos procedimentos de imunização, sendo que o
CAV-1 acomete mais frequentemente cães jovens com idade entre um mês e dois anos de vida (Ettinger e Feldman, 2004; Stalker e Hayes, 2007). Em um levantamento que analisou o soro sanguíneo de cães (Ablet e Baker, 1960) foi observada maior concentração de anticorpos para CAV-1 naqueles que tinham idade superior a seis meses. Aparentemente, não há predileção por sexo ou raça, pois estudos de casos naturais ou experimentais descrevem a doença em ambos os sexos e variadas raças (Larin, 1958).

Pesquisas de anticorpos neutralizantes para o CAV-1 têm demonstrado a presença do vírus na população de canídeos domésticos e silvestres, e também em ursídeos, comprovando que a infecção subclínica está presente com o passar dos anos (Dezengrini et al., 2007; Greene, 2006; Jamilson, 1973; Amundson e Yuill, 1981; Stephenson et al., 1982; Zarnke e Ballard, 1987; Pratelli et al., 2001).

Observações em surtos de infecção por CAV-1 concomitante com outros agentes também demonstraram que a vacinação correta e o cuidado com a desinfecção e higiene são fatores determinantes na prevenção dessa doença (Pratelliet al., 2001). Outros vírus já foram descritos em infecções concomitantes com CAV-1, como por exemplo, o vírus da coronavirose (Pratelliet al., 2001) e o vírus da cinomose (Kobayashi e Itakura, 1993). Como outros adenovírus, CAV-1

\footnotetext{
* Escola de Veterinária da Universidade Federal de Minas Gerais, Av. Antônio Carlos, 6627, Campus Pampulha, CP 567, CEP 30123-970. E-mail: vetmap@hotmail.com

** Escola de Veterinária da Universidade Federal de Minas Gerais, Av. Antônio Carlos, 6627, Campus Pampulha, CP 567, CEP 30123-970. E-mail cambraia@vet.ufmg.br
} 
é resistente à inativação pelo ambiente e também à maioria dos desinfetantes comuns, sendo sensível ao calor, podendo ser inativado após cinco minutos a temperatura entre $56^{\circ} \mathrm{C}$ a $60^{\circ} \mathrm{C}$. CAV-1 sobrevive por dias em fômites contaminados em temperatura ambiente e permanece viável por meses a temperaturas abaixo de $4^{\circ} \mathrm{C}$ (Greene, 2006). A imunização tem tornado a hepatite infecciosa rara em muitos países, mas ainda se tem relatos de surtos esporádicos (Pratelliet al., 2001; Caudell et al., 2005; Decaro et al., 2007). Além disso, em locais onde a doença não é controlada com imunização, é provável que muitos cães adquiram o agente até os dois anos de vida e sofram infecção inaparente ou doença febril discreta com faringite e tonsilite (Stalker e Hayes, 2007).

\section{Patogenia e Transmissão}

O CAV-1 é adquirido por meio de exposição oronasal. Este vírus é encontrado em todos os tecidos, sendo eliminado em todas as secreções durante a infecção aguda. Também é eliminado por pelo menos seis a nove meses na urina após a recuperação do indivíduo. É altamente resistente à inativação, permitindo consequentemente a sua transmissão por meio de fômites e ectoparasitas (Bichard e Sherding, 2004).

Após a exposição oronasal, o CAV-1 replica inicialmente nas tonsilas de onde se dissemina para os linfonodos regionais e vasos linfáticos, antes de atingir o sangue pelo ducto torácico (Greene, 2006). Na tonsila, a inflamação induzida pelo vírus pode ser grave e causar a morte se o edema de laringe for muito extenso (Stalker e Hayes, 2007). O CAV-1 causa viremia e se dissemina para todos os tecidos, especialmente destinando-se aos hepatócitos e às células endoteliais de diversos tecidos. A viremia dura de quatro a oito dias, mas o vírus é liberado na urina por longos períodos (Cullen, 2007). A lesão endotelial pode acometer qualquer tecido, mas o CAV-1 é particularmente notado por seus efeitos no endotélio corneano, glomérulos renais e endotélio vascular (Ettinger e Feldman, 2004).

O CAV-1 tem especial tropismo por endotélio vascular, mesotélio e parênquima hepático, levando a esses locais a formação de edema, hemorragia e necrose hepática. As células do tufo glomerular e as células de Kupffer no fígado são também alvos do vírus (Pay, 1950; Stalker e Hayes, 2007; Koptopoulos e Cornwell, 1981; Givan e Jezéquel, 1969; Herváset al., 1997; Cordón et al., 2001).

O CAV-1 replica no núcleo das células alvo e vírions recémmontados, formando agregados cristalinos, demonstráveis como inclusões basofílicas intranucleares em cortes histológicos são observadas (Quinn et al., 2005). Através de estudo ultraestrutural é possível observar alguns pontos de ruptura da membrana nuclear por onde são liberadas as partículas virais (Givan e Jezéquel, 1969). O CAV-1 causa doença aguda, mas seus antígenos foram identificados também em casos de lesões inflamatórias e de doença hepática crônica (Gocke et al., 1967; Rakich et al., 1986).

\section{Quadro Clínico e Evolução}

Os sinais clínicos causados pela infecção devem-se à lesão celular, tanto dos hepatócitos quanto do endotélio vascular, como resultado dos efeitos diretos da replicação viral. Desta forma, podem ser observadas hemorragias e até mesmo diáteses hemorrágicas provocadas pela lesão endotelial, além de sinais neurológicos causados pelo dano vascular. Esta doença está associada à necrose centrolobular do fígado, peri-hepatite infecciosa, perturbações cardiovasculares e ascite.

A hepatite infecciosa canina pode manifestar-se de forma hiperaguda, aguda e subclínica.

Formas subclínicas, discretas e inaparentes são descritas (Parry e Larin, 1950; Hodgman e Larin, 1953). A taxa de letalidade varia entre 12\% (Parry, 1950) e 25\% (Kelly, 1993). A morte também pode ocorrer de forma superaguda ou aguda (Pay, 1950; Parry e Larin, 1950; Larin, 1958).

$\mathrm{Na}$ forma hiperaguda a doença não é diagnosticada senão após a morte do animal, devido a sua evolução extremamente rápida. Nestes casos, quase sempre os animais vêm a óbito e a suspeita principal é o envenenamento. Muitas vezes, o animal tem morte repentina sem evidenciação de sinais clínicos prévios ou a presença de sinais sutis de doença no dia anterior ao óbito. É mais comum de ocorrer em animais jovens (Greene, 2006).

Na forma aguda, de maneira geral, ocorre duração de dois a sete dias, com período de incubação de dois a cinco dias. Depois de um aumento de temperatura $\left(40^{\circ}\right.$ a $\left.41^{\circ} \mathrm{C}\right)$, os animais mostram apatia e inapetência, e às vezes sensação crescente de sede intensa. Podem ocorrer vômitos e, frequentemente, diarreia que, em determinados casos, pode ser sanguinolenta (Greene, 2006). Pode ocorrer também tonsilite-faringite, linfoadenopatia, edemas cervicais, tosse (pneumonite) e diátese hemorrágica (petéquias equimose epistaxe, melena). Sinais no sistema nervoso central (SNC), tais como desorientação, depressão, estupor, coma, e ataques convulsivos resultantes de encefalopatia hepática, de hipoglicemia ou de encefalite não supurativa (Bichard e Sherding, 2003).

Um quadro crônico da doença pode ocorrer quando em casos agudos, após a ocorrência de necrose centrolobular hepática, houver regeneração se a necrose for limitante e restringir-se somente ao centrolobular. O animal poderá sobreviver, pois haverá regeneração. Se a inflamação hepática continuar, haverá uma progressão para fibrose hepática (Ettinger e Feldman, 1997; Greene, 2006).

Em casos de infecção aguda ou após a recuperação de infecção inaparente podem ocorrer sinais que incluem edema corneano (nublação corneana, também chamada de "olho azul da hepatite" ou "blue eye") e uveíte anterior (blefaroespasmo, inflamação, miose e glaucoma complicante) (Bichard e Sherding, 2003). A formação da uveíte ocorre por formação de complexo imune (hipersensibilidade tipo III ou reação de Arthus), o que produz degeneração e necrose endotelial, resultando em edema corneano (Decaroet al., 2007; Cullen, 2007). Foi experimentalmente demonstrado que os vasos sanguíneos nos olhos de cães com opacidade corneano apresentaram aumento da permeabilidade, o que leva ao edema e ao acúmulo de anticorpos no humor aquoso. Anticorpos presentes no humor aquoso, íris e estroma corneal iniciam a reação de Arthus nas áreas onde o antígeno viral está presente. O infiltrado inflamatório observado em muitos casos contribui para o aumento da pressão 
intraocular e também para o edema corneano (Carmichael, 1964). A uveíte e o edema são geralmente autolimitantes, a menos que complicações adicionais ou destruição endotelial extensa ocorra (Greene, 2006).

A doença pode ser subclínica em animais com imunidade suficiente (isso significa ter um título de anticorpos neutralizantes igual ou maior que 1/500). Cães que demonstram um título parcial de anticorpos $(>1 / 16$ e $<1 / 500)$ nos dias quarto e quinto pós-infecção desenvolveram hepatite crônica e fibrose hepática. Necrose hepática centrolobular ou panlobular disseminada é frequentemente fatal em cães infectados que tenham títulos de anticorpos persistentemente baixos (menor que 1/4) (Greene, 2006; Gocke et al., 1967). Os relatos de encefalite por CAV-1 são geralmente em filhotes com poucas semanas a poucos meses de vida (Caudell et al., 2005; Decaro et al., 2007). O dano endotelial induzido pelo vírus pode levar à coagulação intravascular disseminada (CID) e a diátese hemorrágica, que se manifesta por petéquias e equimoses disseminadas, epistaxe e sangramento contínuo nos locais de punção venosa (Greene, 2006; Cullen, 2007). Em um modelo experimental animal de CID, cinco cães foram inoculados com CAV-1, e desenvolveram CID apresentando alterações como trombocitopenia, disfunção plaquetária, tempo de protrombina prolongado, depressão da atividade do fator VIII da coagulação e aumento dos produtos de degradação da fibrina (Wigton et al., 1976).

Quando a doença clínica fica evidenciada, seu curso é bastante variável, mas frequentemente é breve, e os primeiros sinais se manifestam apenas algumas horas antes da morte do animal (Jones, 2000). Os sinais clínicos dos cães que sobrevivem ao período virêmico agudo incluem principalmente apatia, anorexia, vômito e diarreia com ou sem evidência de sangue. Hiperemia e aumento de volume das tonsilas, associado com faringite e laringite são comuns. Dor abdominal e hepatomegalia são frequentemente aparentes na doença aguda (Greene, 2006; Jones et al., 2000).

A glomerulonefrite ocorre em cães acometidos por hepatite infecciosa canina devido à deposição de imunocomplexos in situ, assim como ocorre em várias outras moléstias infecciosas. Normalmente é pouco relacionada a hepatite infecciosa canina devido à falta de diagnóstico etiológico $(6,21)$. A icterícia é incomum na hepatite infecciosa canina aguda (Parry, 1950; Hodgman e Larin, 1953; Swango, 1997), sendo encontrada em alguns cães que sobrevivem à fase fulminante da doença (Greene, 2006; Smith, 1951). Edema subcutâneo grave da cabeça, pescoço e regiões ventrais do tronco são sinais que podem ocorrer, mas são considerados raros (Wigton et al., 1976; Jones et al., 2000). Muitas vezes os cães não apresentam sinais clínicos e morrem subitamente, o que faz com que os proprietários confundam a doença com intoxicação (Quinn et al., 2005; Greene, 2006; Swango, 1997; Smith, 1951).

\section{Histopatologia e Necropsia}

$\mathrm{Na}$ necropsia as principais lesões macroscópicas observadas incluem petéquias e equimoses disseminadas, líquido serossanguinolento na cavidade abdominal com fibrina, fígado aumentado de volume, com aspecto mosqueado e recoberto por película de fibrina, tonsilas aumentadas e hiperêmicas, e linfonodos edematosos, congestos e, muitas vezes, hemorrágicos. Em alguns casos a quantidade de fibrina pode ser extensa e provocar aderência de vísceras a parede abdominal. Frequentemente a parede da vesícula biliar está espessada por edema (Stalker e Hayes, 2007; Greene, 2006; Cullen, 2007; Jones et al. 2000; Cornwell e Wright, 1969).

Hemorragias podem ocorrer no pulmão, timo e, em uma pequena percentagem de casos no encéfalo ao nível do tálamo, mesencéfalo, tronco encefálico e cerebelo (Stalker e Hayes, 2007; Greene, 2006; Cornwell e Wright, 1969). Em infecções experimentais, hemorragias multifocais foram observadas mais frequentemente no aspecto ventral do encéfalo (Parry, 1950). No estômago observa-se conteúdo líquido sanguinolento e a mucosa está congesta e com petéquias. No intestino há hemorragia subserosa e petéquias na mucosa (Wigton, 1976). Nos linfonodos há necrose e depleção linfoide, degeneração vascular, edema e hemorragia (Wigtonet al., 1976).

As alterações histológicas incluem necrose hepática centrolobular a panlobular. Podem-se observar múltiplos focos de necrose em geral com distribuição predominantemente centrolobular, ao segundo dia pós-infecção (Cornwell e Wright, 1969). Inclusões intranucleares basofílicas aparecem inicialmente em células de Kupffer e posteriormente em hepatócitos íntegros ou parcialmente degenerados adjacentes a áreas de necrose (Greene, 2006; Jones et al., 2000). As inclusões intranucleares frequentemente são redondas, ocupando grande parte do diâmetro nuclear e causando a marginação da cromatina (Parry, 1950). Esse tipo de inclusão intranuclear é chamado de Cowdry tipo A (Ward et al., 1971). As inclusões intranucleares são também descritas no endotélio vascular da maioria dos órgãos (Cornwell e Wright, 1969) e o tipo de célula que desenvolve a inclusão parece estar relacionado com a via de inoculação (Stalker e Hayes, 2007). Nos rins, o principal local de ocorrência de inclusões intranucleares nas células endoteliais é o glomérulo. Essas inclusões raramente estão associadas a qualquer lesão demonstrável no néfron (Stalker e Hayes, 2007; Jones et al., 2000). Porém, há descrição de nefrite intersticial com predomínio de linfócitos e plasmócitos em cães infectados que sobreviveram.

O baço muitas vezes tem aparência macroscópica inalterada, mas na histopatologia observa-se degeneração fibrinoide na camada muscular de artérias, com grandes inclusões intranucleares basofílicas em células endoteliais (Wigton, 1976).

No encéfalo as alterações são essencialmente secundárias à injúria vascular e podem estar ausentes (Stalker e Hayes, 2007). Essas alterações incluem células endoteliais tumefeitas, descamadas em vasos meníngeos e contendo inclusões intranucleares. Vasculite necrosante de pequenas arteríolas e capilares do tálamo ou hemorragia perivascular é descrita ao terceiro dia pós infecção, em casos de infecção experimental (Cornwell e Wright, 1969). Nas meninges são descritas congestão vascular, hemorragia perivascular e inclusões intranucleares basofílicas em células endoteliais (Cornwell e Wright, 1969; Chouinard et al., 1998). Nos olhos geralmente há poucas inclusões intranucleares no endotélio corneano, porém, alguns casos podem apresentar numero- 
sas inclusões intranucleares, como observado em dois cães no 6ํㅜ e 7ํ dias pós infecção (Pursell et al., 1983).

\section{Diagnóstico}

O diagnóstico clínico de hepatite infecciosa canina é difícil de ser dado devido ao curso superagudo ou agudo da enfermidade e a pouca especificidade dos sinais clínicos.

$\mathrm{Na}$ rotina, o diagnóstico de hepatite infecciosa canina é baseado na associação de sinais clínicos, achados de necropsia e histopatologia. Outros métodos de diagnóstico utilizados incluem a técnica de reação de polimerase em cadeia (PCR), isolamento viral, imunofluorescência, microscopia eletrônica e imuno-histoquímica. A técnica de PCR é altamente sensível e específica e pode detectar baixo número de cópias de DNA (Kiss et al., 1996). Em surtos de infecção pelo CAV-1 essa técnica foi utilizada para identificar o agente (Pratelli, 2001; Caudell et al., 2005; Decaro et al., 2007; Park et al., 2007; Swango, 1992).

$\mathrm{O}$ isolamento viral pode ser feito do sangue, secreção da orofaringe, urina e fezes, no período febril. Além disso, na urina há prolongada liberação do vírus após o início da infecção, permitindo o isolamento viral (Woods et al., 1999). A imunofluorescência pode ser usada para demonstrar antígenos de CAV-1 em cortes histológicos ou em lâminas que contenham impressão de tecidos colhidos na necropsia, sendo o rim e fígado os órgãos escolhidos para a realização desta técnica (Woods et al., 1999).

Pela microscopia eletrônica (ME) observam-se partículas virais intranucleares características de adenovírus, que ocorrem em grupos ou dispersas. Alguns grupos de partículas virais aparecem associados com formações cristalinas que são formadas de proteínas. A membrana nuclear apresenta ruptura em alguns pontos e nessas áreas são liberadas partículas virais para o citoplasma (Givan e Jézéquel, 1969). A ME demonstrou a presença de locais de replicação viral nas células glomerulares de um filhote com hepatite infecciosa canina aguda (Hervás et al., 1997).

Em casos de ocorrência natural de hepatite infecciosa canina, e também em infecção experimental, a confirmação da presença de CAV-1 foi feita por imuno-histoquímica (IHQ) (1Caudell et al., 2005; Rakich et al., 1986). Um estudo experimental avaliando a distribuição do antígeno de adenovírus através da técnica de IHQ foi realizado em cervos, e o resultado foi a imunomarcação em células do endotélio vascular de diversos órgãos como língua, mucosa oral, tonsilas, pulmão, rim, rúmen, íleo e cólon (Nelson e Couto, 2001). Embora o diagnóstico definitivo não seja essencial para um tratamento bem-sucedido, a hepatite infecciosa canina pode ser confirmada por meio de testes sorológicos, de isolamento viral, estudos imunofluorescentes ou histopatologia (Bichard e Sherding, 2004).

\section{Prevenção}

A prevenção é conferida por meio de imunização com vacinas contendo CAV-1 e CAV-2, atenuados. A vacinação é altamente efetiva na prevenção da infecção por CAV-1. Administram-se pelo menos duas doses em um intervalo de três a quatro semanas, com oito a dez semanas e com 12 a 14 semanas de idade. Geralmente combina-se o antígeno desta doença com os antígenos da cinomose, coronavirose, parvovirose e traqueobronquite viral. Recomenda-se a revacinação anual, embora a imunização inicial persista por toda a vida (Ettinger e Feldman, 2004).

\section{Tratamento}

O tratamento recomendado é o tratamento suporte até que possa ocorrer recuperação a partir do estágio agudo de infecção e regeneração hepatocelular. Isso geralmente requer fluidoterapia que utilize de soluções suplementadas com potássio e dextrose, tratamento para encefalopatia hepática e antibióticos para complicações bacterianas secundárias (Bichard e Sherding, 2004).

\section{Relato de caso}

Uma cadela, da raça Fox Paulistinha, com quatro meses de idade, 4,4 kg de peso, domiciliada, em processo de imunização (duas doses da vacina polivalente) apresentou histórico de vômito intermitente. A cadela fazia pequenos passeios na rua e havia tido contato recente com outros cães. Durante um banho, no qual foi utilizado xampu à base de permetrina, foi observado que a cadela havia se lambido. Passadas poucas horas, a cadela começou a vomitar com frequência.

Durante o primeiro exame físico, que ocorreu na manhã seguinte aos primeiros sinais clínicos, observou-se desidratação moderada, apatia, inapetência e discreto aumento da sensibilidade dolorosa à palpação abdominal. O animal permaneceu internado durante o dia, recebendo medicação de suporte $(0,5 \mathrm{mg} / \mathrm{kg} / \mathrm{q} 8 \mathrm{hs}$ de metoclopramida por via endovenosa, e $1 \mathrm{mg} / \mathrm{kg} / \mathrm{q} 12 \mathrm{hs}$ de ranitidina, por via subcutânea) e fluidoterapia endovenosa (30 ml/kg durante 12 horas de ringer com lactato de sódio alternando com solução fisiológica $0,9 \%$ adicionada de $1 \mathrm{ml} / \mathrm{kg}$ deglicose $50 \%$ ). Durante todo o período de tratamento e em casa, onde passava a noite, recebeu metoclopramida via oral e sachet eletrolítico para misturar em água.

Logo no primeiro dia de tratamento, mesmo com a medicação, os vômitos continuaram e a cadela começou a apresentar diarreia fétida e amarelada. Foram realizados dois exames parasitológicos de fezes ( 1 으 e $2^{\circ}$ dias), entretanto, nada foi constatado.

Entre o segundo e terceiro dias a diarreia passou de amarelada à acinzentada, e posteriormente esverdeada e, por fim, avermelhada e liquefeita. Com a evolução do quadro, foi também constatado discreto espessamento das alças intestinais. O primeiro hemograma realizado ( $3^{\circ} \mathrm{dia}$ ) revelou apenas discreta trombocitopenia $\left(129.000 \times 10^{3} \mathrm{cé} / \mathrm{s} / \mathrm{ìL}\right)$, enquanto as concentrações séricas de glicose apresentavam-se dentro dos limites de referência e a urinálise também não apresentava nada digno de nota.

No quarto dia foi solicitado exame ultrassonográfico onde foi observada ascite discreta, enquanto os órgãos e estruturas abdominais não apresentavam alterações. O animal começou a apresentar, então, fezes com sangue. Além da medicação de suporte e fluidoterapia, foram introduzidos ao tratamento vitaminas do complexo B $(1 \mathrm{ml} / \mathrm{animal} / \mathrm{q} 24 \mathrm{~h}$, por via endovenosa, enrofloxacina $(2,5 \mathrm{mg} / \mathrm{kg} / \mathrm{q} 12 \mathrm{hs}$, por via subcutânea) e nutrição parenteral (solução de aminoácidos 
a $10 \%$ + glicose $50 \%$ + solução de Lipídeos a $20 \%$ ), que se seguiram até o último dia de tratamento, à exceção da enrofloxacina, posteriormente substituída pela doxiciclina.

No quinto e sexto dia, o quadro clínico da cadela permanecia o mesmo, havendo em alguns poucos momentos, alguns sinais de melhora.

No sétimo dia o animal passou a apresentar blefaroconjuntivite bilateral purulenta, icterícia (observada principalmente na mucosa ocular e na região ventral do abdome) e sinais neurológicos (balançava a cabeça de um lado para outro e apoiava-a contra a parede). Foi tratada com corticoide (prednisona, $1 \mathrm{mg} / \mathrm{kg} / \mathrm{q} 24 \mathrm{hs}$, por via intramuscular, por três dias) e com colírio antibiótico à base de tobramicina (uma gota em cada olho, seis $x$ ao dia), o que promoveu a resolução dos sinais oculares. Os vômitos persistiam e a diarreia passou a ser do tipo melena, evoluindo para o aparecimento de sangue vivo nas fezes. Neste momento foram solicitados exames para cinomose, leptospirose, parvovirose, hemobartonelose e erliquiose, cujos resultados foram negativos, enquanto o resultado do exame para babesiose (PCR) foi positivo.

$O$ resultado do segundo hemograma (70 dia) apresentou anemia, anisocitose, trombocitopenia $\left(92.000 \times 10^{3} \mathrm{cé} / \mathrm{s} / \mu \mathrm{L}\right)$ enquanto os leucócitos estavam inalterados. Os exames de bioquímica sérica das funções renal e hepática revelaram azotemia $(317,50 \mathrm{mg} / \mathrm{dL}$ de ureia e $5,77 \mathrm{mg} / \mathrm{dL}$ de creatinina) e enzimas hepáticas elevadas (132 U/L de TGP, $256 \mathrm{U} / \mathrm{L}$ de FA, e $15,85 \mathrm{mg} / \mathrm{dL}$ de bilirrubina total). Não havia alterações significativas na urinálise. $O$ soro estava ictérico neste $7^{\circ}$ dia de tratamento, então a enroflaxina foi substituída pela doxiciclina (5 mg/kg/q12hs, via endovenosa) e imidocarb (5 mg/ $\mathrm{kg}$, por via subcutânea, em dose única) e passou-se a administrar a associação de aminoácidos essenciais e alfacetoanálogos por via oral (1 tablete para cada $5 \mathrm{~kg} / \mathrm{q} 24 \mathrm{~h}$ ).

Foi aumentada a quantidade de fluidoterapia endovenosa (50 ml/kg durante 12 horas) e passou-se a administrar furosemida por via subcutânea ( $2 \mathrm{mg} / \mathrm{kg} / \mathrm{q} 8 \mathrm{~h}$ ).

A partir deste 70 dia foram realizados exames consecutivos e o hemograma seguinte $\left(9^{\circ} \mathrm{dia}\right)$ revelou piora, com aumento da anemia, da trombocitopenia $\left(76.000 \times 10^{3} \mathrm{cé} / \mathrm{s} / \mu \mathrm{L}\right)$ e leucocitose (neutrofilia e linfopenia), enquanto a bioquímica sanguínea renal apresentou valores ainda maiores de ureia $(400,30 \mathrm{mg} / \mathrm{dL})$ e de creatinina $(5,35 \mathrm{mg} / \mathrm{dL})$. A bilirrubina direta elevou-se para $30,60 \mathrm{mg} / \mathrm{dL}$ e a dosagem de sódio apresentou o valor de $157 \mathrm{mmol} / \mathrm{dL}$. Foi mantido o tratamento com fluidoterapia, furosemida e alfacetoanálogos e os exames realizados 24 horas após os anteriores (10 dia) revelaram piora na anemia, discreta elevação nos valores das plaquetas $\left(124.000 \times 10^{3} \mathrm{cé} / \mathrm{s} / \mu \mathrm{L}\right)$ e leucocitose (linfocitose), enquanto o perfil sanguíneo renal apresentou melhora discreta nos valores de ureia $(374,5 \mathrm{mg} / \mathrm{dL})$ e mais marcante nos valores de creatinina $(2,15 \mathrm{mg} / \mathrm{dL})$. Em relação às enzimas hepáticas, a TGP e a FA apresentaram valores mais elevados que os anteriores $(446 \mathrm{U} / \mathrm{L}$ e $366,7 \mathrm{U} / \mathrm{L}$, respectivamente). Neste momento os valores de bilirrubina direta eram de 19,70 mg/dL. O soro passou a apresentar-se fortemente ictérico. A biópsia hepática foi indicada, mas não autorizada pelo proprietário. No dia seguinte (110 dia de tratamento) o hemograma mostrou anemia mais severa, elevação das plaquetas $\left(195.000 \times 10^{3} \mathrm{cé} / \mathrm{s} / \mu \mathrm{L}\right)$ e leucocitose acentuada (44.900 céls./ $\mu \mathrm{L}$ ). A bioquímica sérica renal neste momento apresentou valores de $349,6 \mathrm{mg} / \mathrm{dL}$ de ureia e 4,89 $\mathrm{mg} / \mathrm{dL}$ de creatinina, e a bilirrubina havia elevado novamente (de 19,70 para 26,99). O fósforo foi medido no sangue e apresentava-se bastante elevado $(18,90 \mathrm{mg} / \mathrm{dL})$. O soro continuava ictérico.

Além do tratamento de suporte foi feita transfusão de sangue. Um novo hemograma (12이이 revelou que a série vermelha havia normalizado, mas a leucocitose continuava, enquanto a ureia e a creatinina séricas haviam aumentado $(367,20$ $\mathrm{mg} / \mathrm{dL}$ e $4,89 \mathrm{mg} / \mathrm{dL}$, respectivamente).

O tratamento foi mantido, mas a cadela já não estava tão responsiva quanto antes, além de passar a apresentar o abdome mais distendido e com mais fluido. Este líquido ascítico foi drenado e coletado para análise, revelando moderada celularidade, composta por neutrófilos degenerados, macrófagos ativos, células mesoteliais e eritrócitos, além de intensa eritrofagocitose. $\mathrm{Na}$ impossibilidade de hemodiálise (peso do animal insuficiente) foi realizada uma diálise peritoneal.

No dia seguinte (13잉 foi realizada nova medida de ureia e creatinina séricas, entretanto não houve redução significativa da ureia $(367,20$ para 330,00$)$ e da creatinina $(4,89$ para 4,19$)$. Neste 13 o dia, o hemograma praticamente não se alterou. A cadela estava clinicamente muito apática, apresentando vômito e diarreia com sangue. O padrão respiratório era longo e suspiroso e ela já estava agonizando, quando então, optou-se pela eutanásia do animal.

$\mathrm{O}$ animal foi acompanhado durante 13 dias apresentando períodos de melhora (com diminuição da apatia, dos vômitos e da diarreia, além do retorno ao consumo voluntário de água) alternados com períodos de piora do quadro clínico, entretanto, em nenhum momento voltou a ingerir alimento, ou apresentou febre.

A necropsia foi realizada e evidenciada grande quantidade de líquido de coloração acastanhada na cavidade abdominal; estriações hemorrágicas ao longo da mucosa intestinal; pâncreas edemaciado e com aumento de tamanho; estômago com lesão circular profunda na mucosa (úlcera), alcançando à serosa; fígado de coloração acastanhada e, em um dos lobos, uma lesão severa necrótica, além de rins com coloração acastanhada de mesma aparência do fígado.

Ao exame histopatológico, o pâncreas apresentou lesões de natureza circulatória, além de congestão e edema agudo, enquanto as células acinares apresentavam-se tumefeitas e vacuolizadas. O rim apresentava intensa hiperemia, os túbulos renais apresentavam-se tumefeitos, o citoplasma vacuolizado e com grande quantidade de pigmento biliar. Em muitos túbulos renais, cilindros homogêneos foram observados. Os glomérulos apresentavam exsudação de material proteico ligeiramente eosinofílico. A conclusão foi de glomerulonefrite com lesões degenerativas devido à intensa presença de bilirrubina. Com relação ao fígado, este apresentava necrose mamária de lóbulos hepáticos, além de serem visualizados focos hemorrágicos e congestão severa. Notou-se hiperplasia e proliferação desordenada de ductos biliares, associado a severa colestase intra-hepática. Os hepatócitos remanescentes apresentavam-se muitos tumefeitos e vacuolizados, além de estarem hiperplásicos e desorganizados. Muitos hepatócitos apresentavam corpús- 
culos de inclusão intranucleares característicos da hepatite infecciosa canina. Também foram verificados alguns focos de inflamação com histiócitos, linfócitos e neutrófilos. A lesão hepática era aguda, severa e incompatível com a vida histológica.

\section{Discussão}

Os sinais clínicos iniciais apresentados levaram à suspeita de um quadro de intoxicação por permetrina, pela associação lógica com o fato da cadela ter ingerido esta substância durante um banho e estes sinais terem aparecido poucas horas após o ocorrido. Como a medicação realizada para o controle dos vômitos não foi eficaz, e foi constatado discreto espessamento das alças intestinais à palpação abdominal, pensou-se na possibilidade de intussuscepção, na suspeita do animal ter ingerido um corpo estranho, característico de cães nessa faixa etária. Foi então pedido exame de ultrassom. Visto que o resultado do US indicou ausência de intussuscepção, e a presença de sangue nas fezes era persistente, pensou-se em verminose, porém, os exames de fezes realizados no primeiro e segundo dias revelaram resultados negativos.

Entre o terceiro e sétimo dias, numa tentativa de recuperação da homeostasia, o tratamento do animal continuou baseado nos sinais clínicos, porém a preocupação do clínico responsável aumentou, visto que não havia qualquer sinal de melhora do paciente.

Em geral, animais em fase de crescimento estão mais sujeitos a certas doenças, comuns a esta faixa etária, como as doenças virais (parvovirose, coronavirose, cinomose e hepatite infecciosa). O curso dessas doenças é conhecido dos clínicos e, em geral, animais doentes ou apresentam melhora do quadro cerca de cinco dias depois de iniciado os sinais clínicos, ou vem a óbito. No caso em tela, decorridos sete dias e o animal apresentando ainda sinais clínicos de vômito e diarreia, além de alterações oculares e neurológicas. Esse dia foi decisivo para a tomada de decisões. Aliado à disposição do proprietário do animal em ver o restabelecimento da cadela, o clínico montou uma estratégia, ampliando seu quadro de diagnóstico diferencial, solicitando, nesse momento, uma sequência de exames importantes, que iriam também contribuir para a conduta a ser tomada. A fim de descartar doenças passíveis de serem identificadas por exames complementares, foram solicitadas provas de identificação de cinomose, leptospirose, parvovirose, haemobartonelose, erliquiose e babesiose. Os resultados de todos esses exames foram negativos, exceto o para babesiose (PCR). Nesse momento, os sinais clínicos apresentados pela cadela condiziam com um quadro de babesiose (anemia hemolítica regenerativa, trombocitopenia, insuficiência renal, icterícia, anorexia, letargia, ascite, sinais gastrintestinais, acometimento do SNC, edema, hiperbilirrubi-

\section{Considerações finais}

A hepatite infecciosa viral canina é uma doença rara, que vem sendo controlada pelo estímulo antigênico provocado pelas imunizações polivalentes. Além dos sinais clínicos serem inespecíficos, a raridade com que ocorre dificulta o diagnóstico, que, muitas vezes, só é conseguido de maneira nemia) (Ettinger e Feldman, 2004). Por esse fato, todas as atenções foram voltadas para esta enfermidade. Optou-se pela troca de antibiótico e foi aplicada medicação específica para tratamento de babesiose. Mesmo que o tempo não tenha sido suficiente para observar reversão do quadro clínico, após a introdução dos medicamentos específicos, não houve nenhum indício de melhora clínica. Os distúrbios neurológicos e gastrintestinais observados, aliados às alterações vistas nos resultados dos exames de função hepática conduziram, naquele momento, à suspeita de um quadro de encefalopatia hepática.

Doenças hepáticas, principalmente aquelas que provocam redução da massa hepática funcional, associadas ou não a comprometimento de função excretora renal, foram então aventadas e a hepatite infecciosa canina passou a ser considerada. A hepatite infecciosa canina é doença que provoca lesões nas células endoteliais e hepáticas, levando, portanto, a hemorragias e icterícia (Ettinger e Feldman, 2004), podendo, ainda, causar ulceração e hemorragia gastrintestinal de patogenia não conhecida (Nelson e Couto, 2001). A realização de diálise peritoneal na esperança de conseguir diminuir a azotemia uma vez que o animal não tinha peso suficiente para fazer uma hemodiálise, poderia trazer um benefício temporário, porém, não apresentou bons resultados; os valores de ureia e creatinina tiveram uma diminuição não muito significativa. A literatura menciona a ocorrência de leucopenia, neutropenia, linfopenia e trombocitopenia de moderadas a grave, presentes no início das manifestações clínicas e a distensão abdominal observada é em função de ascite do tipo serossanguinolenta, como resultado de hipertensão porta intra-hepática, devido à pressão hidrostática porta estar aumentada, assim como pela maior retenção de sódio (Ettinger e Feldman, 2004; Nelson e Couto, 2001). Sinais oculares como uveíte e edema de córnea também podem ser observados, assim como glomerulonefrite e necrose hepática centrolobular (Ettinger e Feldman, 2004). No animal em questão os sinais de glomerulonefrite, mesmo que não específicos, ficaram registrados pelas alterações da função excretora renal. $O$ diagnóstico in vivo de hepatite infecciosa canina só é confirmado pela demonstração de aumento no título do anticorpo em amostras séricas pareadas Ettinger e Feldman, 2004, entretanto, não é rotina do clínico veterinário solicitar este exame, visto que esta é uma enfermidade de rara ocorrência. O diagnóstico definitivo só foi possível após o resultado do exame histopatológico, revelando a presença de corpúsculos de inclusão intranucleares. Ainda de acordo com (Ettinger e Feldman, 2004), a maioria dos cães recupera-se com terapia de suporte. Em relação à cadela estudada, entretanto, o tratamento de suporte aplicado permitiu apenas uma sobrevida maior, pois, mesmo com apoio completo fornecido pela fluidoterapia, nutrição parenteral, alfacetoanálogos e outros medicamentos, não se evitou a piora da paciente.

definitiva, após a morte do animal, quando, a partir de exame histológico, é possível visualizar os corpúsculos de inclusão intranucleares nos hepatócitos.

A maior sobrevida deste animal permitiu observar as graves consequências provocadas pela hepatite infecciosa viral canina. 


\section{Referências}

INNES, JRM, SAUNDERS, LZ. Comparative Neuropathology. New York: Academic Press, 1962.

PARRY, HB. Viral hepatitis of dogs (Rubarth's disease. Clinical and pathological observations on a spontaneous epidemic. Veterinary, Record, 1950, v. 62, n. 38, p. 559-565.

PAY, TWF. Infectious canine hepatitis (Hepatitis contagiosacanis [Rubarth]). VeterinaryRecord, 1950, v. 62, n. 38, p. 551-558.

HIPÓLITO, O, FREITAS, M. Doenças Infecto - Contagiosas dos Animais Domésticos. São Paulo: Edições Melhoramentos, 1964.

QUINN, PJ et al. Adenoviridae. In: QUINN, PJ; MARKEY, BK; CARTER, ME, DONNELLY, W J. Microbiologia Veterinária e Doenças Infecciosas. Porto Alegre: Artmed, 2005, v. 56, p. 323-326.

ETTINGER, SJ, FELDMAN, EC. Tratado de Medicina Interna Veterinária. 5. ed. Rio de Janeiro: Guanabara Koogan, 2004.

STALKER, MJ, HAYES, MA. The liver and biliary system. In: JUBB, KFV et al. Pathology of Domestic Animals. 5th ed. San Diego: Academic Press, 2007, v. 2, n. 8, p. 348-351.

ABLET, RE, BAKER, LA. The development in the dog of naturally acquired antibody to canine hepatitis in relation to age. Veterinary Record, 1960, v. 72, n. 51, p. 1202.

LARIN, NM. Epidemiological studies of canine virus hepatitis (Rubarth's disease). Veterinary Record, 1958, v. 70, n. 14, p. 295-297.

DEZENGRINI, R, WEIBLEN, R, FLORES, EF. Soroprevalência das infecções por parvovírus, adenovírus, coronavírus canino e pelo vírus da cinomose em cães de Santa Maria, Rio Grande do Sul, Brasil. Ciência Rural, 2007, v. 37, n. 1, p. 183-189.

GREENE, CE. Infectious canine hepatitis and canine acidophil cell hepatitis. In: GREENE CE, editor. Infectious disease of the dog and cat, 3th ed. Philadelphia: Saunders-Elsevier, 2006, v. 8, p. 41-47.

JAMILSON, RK et al. Survey for antibodies to canine viruses in selected wild mammals. Journal of Wildlife Diseases, 1973, v. 9, n. 1, p. 2-3. AMUNDSON, TE, YUILL, TM. Prevalence of selected pathogenic microbial agents in the red fox (Vulpesfulva) and gray fox (Urocyoncinereoargenteus) of southwestern Wisconsin. Jounal of Wildlife Diseases, 1981, v. 17, n. 1, p. 17-22.

STEPHENSON, RO et al. Serologic survey for canine distemper and infectious canine hepatitis in wolves in Alaska. Journal of Wildlife Diseases, 1982, v. 18, n. 4, p. 419-424.

ZARNKE, RL, BALLARD, WB. Serologic survey for selected microbial pathogens of wolves in Alaska, 1975-1982. Journal of Wildlife Diseases, 1987, v. 23, n. 1, p. 77-85.

ZARNKE, RL, EVANS MB. Serologic survey for infectious canine hepatitis virus in Grizzly bears (UrsusArctos) from Alaska, 1973 to 1987. Journal of Wildlife Diseases, 1989, v. 25, n. 4, p. 568-573.

PRATELLI, A et al. Severe enteric in an animal shelter associated with dual infections by canine adenovirus type 1 and canine coronavirus. Journal Veterinary Medicine B. Infectious diseases and veterinary public health, 2001, v. 48, n. 5, p. 385-392.

KOBAYASHI, YK, ITAKURA, C. Dual infection with canine distemper virus and infectious canine hepatitis virus (canine adenovirus type 1) in a dog. Journal of Veterinary Medical Science, 1993, v. 55, n. 4, p. 699-701.

CAUDELL, D et al. Diagnosis of infectious canine hepatitis virus (CAV1) infection in puppies with encephalopathy. Journal Veterinary Diagnostic Investigation, 2005, v. 17, n. 1, p. 58-61.

DECARO, $\mathrm{N}$ et al. Infectious canine hepatitis: an "old" disease reemerging in Italy. Research in Veterinary Science, 2007, v. 83, n. 2, p. 269-273.

BICHARD, SJ, SHERDING, RG. Clínica de Pequenos Animais. São Paulo: Roca, 2004.
CULLEN, JM. Liver, biliary system and exocrine pancreas. In: MCGAVIN, MD,ZACHARY JF. Pathologic basis of veterinary disease, 4th ed. St Louis: Mosby-Elsevier;2007, p.393-461.

KOPTOPOULOS, G, CORNWELL, HJC. Canine adenovirus: a review. The Veterinay Bulletin, Wallingford, 1981, v. 51, n. 3, p. 135-141.

GIVAN, KF, JÉZÉQUEL, A. Infectious canine hepatitis: a virologic and ultrastructural study. Laboratory Investigation, 1969, v. 20, n. 1, p. 36-45.

HERVÁS, J et al. Focal mesangial-sclerosing glomerulonephritis and acutespontaneous infectious canine hepatitis: structural, immunohistochemical and subcellular studies. Veterinary Immunology and Immunopathology, 1997, v. 57, n. 1-2, p. 25-32.

CORDÓN, P J et al. Glomerulonephritis associated with simultaneous canine adenovirus-1 and Dirofilariaimmitisinfection in a dog. Journal of Veterinary Medicine. B, Infectious diseases and veterinary public health, 2001, v. 49, n. 5, p. 235-239.

GOCKE, DJ et al. Experimental viral hepatitis in the dog: the production of persistent disease in partially immune animals. Journal of Clinical Investigation, 1967, v. 46, n. 9, p. 1506-1517.

RAKICH, PM, PRASSE, KW, LUKERT, PD, CORNELIUS, LM. Immunohistochemical detection of canine adenovirus in paraffin sections of liver. Veterinary Pathology, 1986, v. 23, n. 4, p. 478-484. PARRY, HB, LARIN, NM. The natural history of virus hepatitis of dogs (Rubarth's disease). Veterinary Record, 1950, v. 63, p. 833-847.

LARIN, N.M. Epidemiological studies of canine virus hepatitis (Rubarth's disease). Veterinary Record, 1958, v. 70, n. 14, p. 295-297.

HODGMAN, SFJ, LARIN, NM. Diagnosis of canine virus hepatitis (Rubarth's disease). Veterinary Record, 1953, v. 65 n. 29, p. 447450.

KELLY, WR. The liver and biliary system. In: JUBB, KFV, KENNEDY, PC, PALMER N. Pathology of Domestic Animals. 4th ed. San Diego: Academic Press; 1993. p.319-406.

BICHARD, SJ, SHERDING, RG. Clínica de Pequenos Animais. São Paulo: Roca, 2003.

WIGTON, et al. Infectious canine hepatitis: animal model for viralinduced disseminated intravascular coagulation. Blood 1976, v. 46, n. 2, p. 287-296.

CARMICHAEL, LE. The pathogenesis of ocular lesions of infectious canine hepatitis. 1. Pathology and virological observations. PathologiaVeterinaria, 1964, v. 1, n. 1, p. 73-95.

JONES, TC et al. Moléstias causadas por agentes virais. In: JONES, TC; HUNT, RD; KING, NW. Patologia Veterinária. 6. ed. São Paulo: Manole; 2000. p. 249-253.

SWANGO, L.J. Moléstias virais caninas, p. 573-588. In: ETTINGER, SJ e FELDMAN, EC. Tratado de Medicina Interna Veterinária. São Paulo: Manole, 1997, $3020 \mathrm{p}$.

SMITH, DLT. Observations on infectious canine hepatitis. American Journal of Veterinary Research, 1951, v. 12, n. 1, p. 38-43.

CORNWELL, HJC, WRIGHT, NO. The pathology of experimental infectious canine hepatitis in neonatal puppies. Research in Veterinary Science, 1969, v. 10, n. 2, p. 156-160.

WARD, FP, FAIRCHILD, DG, VUICICH, JV. Inclusion body hepatitis in a prairie falcon. Journal of Wildlife Diseases, 1971, v. 7, n. 2, p. 120 124.

PURSELL, AR et al. Isolation of an adenovirus from black bear cubs. Journal of Wildlife Diseases, 1983, v. 3, n. 19, p. 269-271.

CHOUINARD, $L$ et al. Use of polymerase chain reaction and immunohistochemistry for detection of canine adenovirus type 1 in formalin-fixed, paraffin-embedded liver of dogs with chronic hepatitis or cirrhosis. Journal Veterinary Diagnostic Investigation, 1998, v. 10 , n. 4, p. 320-325. 
KISS, I et al. Infectious canine hepatitis: detection of canine adenovirus type 1 bypolymerase chain reaction. Acta Veterinaria Hungarica, 1996, v. 44, n. 2, p. 253-258.

PARK, NY et al. Canine adenovirus type 1 infection of a eurasian river otter (Lutralutra). Veterinay Pathology, 2007, v. 44, n. 4, p. 536-539.

SWANGO, LJ. Infectious canine hepatitis and Viraltracheobronchitis. In: CASTRO AE e HEUSCHELE WP. Veterinary Diagnostic Virology. A practitioner's guide. St. Louis, Ed. Mosby Year Book; 1992, p. 143-146.
WOODS, LW et al. Lesions and transmission of experimental adenovirus hemorrhagic disease in black-tailed deer fawns. Veterinary Pathology, v. 36, n. 2, p. 100-110.

NELSON, RW, COUTO, CG. Medicina Interna de Pequenos Animais. 2. ed. Rio de Janeiro: Guanabara Koogan, 2001. 